\title{
Prevention of arachidonic acid-induced liver injury by controlling oxidative stress-mediated transglutaminase activation with garlic extracts
}

\author{
XIAN-YANG QIN, TING SU and SOICHI KOJIMA*
}

Liver Cancer Prevention Research Unit, RIKEN Center for Integrative Medical Sciences, Wako, Saitama 351-0198, Japan

Received May 27, 2019; Accepted September 10, 2019

DOI: $10.3892 / \mathrm{etm} .2019 .8384$

\begin{abstract}
Garlic and its sulfur constituents have numerous biological functions, such as antioxidant, anti-inflammatory, anti-microbial, anticancer, antidiabetic and cardioprotective effects. Fatty liver diseases, such as non-alcoholic steatohepatitis, which is characterized by the accumulation of lipids and oxidative stress in hepatocytes and continual liver damage, has attracted much attention, and it is believed that it will become the leading etiology of liver cancer. We have previously reported that the growth-suppressive effects of arachidonic acid (AA), an unsaturated fatty acid known to be a pro-inflammatory precursor, is accompanied by the production of reactive oxygen species followed by the nuclear accumulation and activation of the protein crosslinking enzyme, transglutaminase (TG)2. In this study, we examined the potential role of garlic extracts in preventing the growth-suppressive effects of AA on human hepatic cells. We also aimed to provide a mechanistic insight regarding the association between the hepatoprotective effects of garlic extract and the inhibition of the TG-related crosslinking of nuclear proteins, which is not associated with hepatic lipid partitioning mediated by stearoyl-CoA desaturase-1. Given the critical roles of unsaturated fatty acids in the regulation of cancer cell stemness and immune surveillance in the context of chronic injury, we propose that garlic extracts may serve as a therapeutic option for the prevention of chronic liver injury and inflammation, as well as for the prevention of the carcinogenesis of fatty livers.
\end{abstract}

Correspondence to: Dr Xian-Yang Qin, Liver Cancer Prevention Research Unit, RIKEN Center for Integrative Medical Sciences, Wako, Saitama 351-0198, Japan

E-mail: xyqin@riken.jp

"Deceased

Key words: garlic extracts, arachidonic acid, oxidative stress, hepatic cell injury, nuclear transglutaminase 2

\section{Introduction}

Garlic (Allium sativum L.) is known to play important roles in diet and traditional medicine for centuries (1). A number of in vitro and in vivo studies have demonstrated that garlic extracts have numerous biological functions, such as antioxidant (1), anti-inflammatory (2), antimicrobial (3), anticancer (4), antidiabetic (5) and cardioprotective effects (6). Additionally, garlic extracts have been shown to exert hepatoprotective effects against acute hepatic injury (7), non-alcoholic steatohepatitis (NASH) (8) and hepatocellular carcinoma [HCC; International Classification of Diseases for Oncology (ICD-O) code: 8170/3] (9), partly by targeting the LRP6/Wnt signaling pathway (9). Supplementation with allicin, a compound found in fresh aqueous extracts of garlic, has been shown to exert protective effects against alcoholic fatty liver disease by improving inflammatory conditions and exerting antioxidant effects (10).

Lipid-associated inflammation, which leads to repeated liver injury and compensatory proliferation, has recently become the leading etiology of HCC (11). Non-alcoholic fatty liver disease has been reported to contribute to $10-12 \%$ of HCC cases in Western populations and 1-6\% of HCC cases in Asian populations (12). We have previously reported that arachidonic acid (AA), an unsaturated fatty acid known to be a pro-inflammatory precursor and the levels of which are increased during hepatic tumorigenesis, is a target for the chemoprevention of HCC by acyclic retinoid, a novel anticancer agent $(13,14)$. On the other hand, we found that the nuclear accumulation of the protein crosslinking enzyme transglutaminase (TG)2 under conditions of oxidative stress plays a critical role in regulating cell death in the liver, partly by crosslinking and inactivating the transcription factor, Sp1 $(15,16)$. Recently, a mechanistic study by our group revealed that the suppression of cell growth by AA accompanied the production of reactive oxygen species (ROS) followed by the activation of nuclear TG2 in hepatic cells, suggesting a critical role of the ROS-mediated activation of nuclear TG2 by AA in chronic liver injury and inflammation (17).

In this study, we investigated the protective effect of garlic extracts against AA-induced cell death in hepatic cells and aimed to elucidate the underlying mechanism associated with ROS/TG2-dependent signaling pathways. 


\section{Materials and methods}

Chemicals. Aged garlic extracts (AGEs) and the water-soluble compound, $S$-allylmercaptocysteine (SAMC), were provided by Wakunaga Pharmaceutical Co., Ltd. AA (A9673) and the ROS inhibitor, $N$-acetyl-L-cysteine (NAC; A7250), were obtained from Sigma-Aldrich. The irreversible TG inhibitor, Z-DON-Val-Pro-Leu-OMe (ZDON; Z006), was purchased from Zedira, as previously described (17).

Cell culture. The human liver cancer cell line, JHH7 (also known as FLC7), was kindly supplied by Professor T. Matsuura of the Jikei University School of Medicine, Tokyo, Japan (18). The cells were maintained in Dulbecco's modified Eagle's medium (Wako Industries) containing $10 \%$ fetal bovine serum (Mediatech), $100 \mathrm{U} / \mathrm{ml}$ penicillin/streptomycin and $2 \mathrm{mmol} / \mathrm{l}$ L-glutamine (Mediatech) and were grown at $37^{\circ} \mathrm{C}$ in a humidified incubator under $5 \% \mathrm{CO}_{2}$ as previously described (19). The cells were seeded at a concentration of 100,000 cells $/ \mathrm{ml}$ and cultured in serum-containing medium for $24 \mathrm{~h}$ prior to chemical treatment. $\mathrm{H}_{2} \mathrm{O}$ was used as the solvent control for SAMC. Ethanol (EtOH) was used as the solvent control for AA. The doses and treatment times of the chemical treatments are shown and explained in detail in the figures and figure legends.

Cellular ROS detection. Cellular ROS levels were determined using the chloromethyl derivative of 20,70-dichlorodihydrofluorescein diacetate $\left(\mathrm{CM}-\mathrm{H}_{2} \mathrm{DCFDA}\right.$; Life Technologies; Thermo Fisher Scientific), a general oxidative stress probe, as previously described (16). Following chemical treatment for $16 \mathrm{~h}$ for AA treatment or $4 \mathrm{~h}$ for SAMC treatment, the cells were monitored for FITC fluorescence signals using a plate reader (ARVO MX; Perkin Elmer Inc.).

Determination of cell viability. The number of viable cells was determined using the Cell Counting Kit-8 (Dojindo Molecular Technologies, Kumamoto, Japan) in a plate reader (ARVO MX; Perkin-Elmer Inc.) at $450 \mathrm{~nm}$ as previously described (19).

Determination of cellular TG2 activity. The cellular activity of TG2 was measured based on the incorporation of $0.2 \mathrm{mM}$ 5-biotinamidopentylamine (5-BAPA, 21345; Thermo Fisher Scientific) into the cells as previously described (16). The cells were then washed and stained with TRITC-conjugated secondary antibody (1:500, 016-020-084; Jackson ImmunoResearch Laboratories) for $20 \mathrm{~min}$ at room temperature and cell nuclei were visualized using DAPI for $20 \mathrm{~min}$ at room temperature. Images were captured using an ImageXpress Micro Confocal High-Content Imaging System (Molecular Devices). The morphological analysis was performed using MetaXpress Image Analysis software version 5.1 (Molecular Devices).

shRNA lentiviral particle transduction. Stearoyl-CoA desaturase-1 (SCD1; sc-36464-V) and control (sc-108080) short hairpin RNA (shRNA) lentiviral particles were obtained from Santa Cruz Biotechnology. The cells were transduced with lentiviral vectors expressing the shRNAs at approximately 0.5 multiplicity of infection (MOI) using $5 \mu \mathrm{g} / \mathrm{ml}$ Polybrene (Santa Cruz Biotechnology) and then selected with $2 \mu \mathrm{g} / \mathrm{ml}$ puromycin-containing culture medium for $>1$ month for further analysis.

Reverse transcription-quantitative PCR (RT-qPCR). Total RNA was isolated from the cells using an RNeasy kit (Qiagen) and quantified using a NanoDrop spectrophotometer (NanoDrop Products) in accordance with the manufacturer's instructions. cDNA was synthesized using a PrimeScript RT Master Mix Kit (Takara Bio). The sequences of the primers used were as follows: Glyceraldehyde 3-phosphate dehydrogenase (GAPDH) forward, CAATGACCCCTTCATTGACC and reverse, GACAAGCTTCCCGTTCTCAG; and SCD1 forward, GTACCGCTGGCACATCAACTT and reverse, TTGGAG ACTTTCTTCCGGTCAT. PCRs were performed using a combination of the Roche LightCycler 96 Real-Time PCR System (Roche Diagnostic Co., Ltd.) and SYBR Premix ExTaq II (Takara Bio) under the following cycling conditions: $95^{\circ} \mathrm{C}$ for $10 \mathrm{~min}$, followed by 40 cycles of $95^{\circ} \mathrm{C}$ for $10 \mathrm{sec}$ and $60^{\circ} \mathrm{C}$ for $10 \mathrm{sec}$. Relative gene expression analysis calculation was performed using the $\Delta \Delta \mathrm{Cq}$ method (20).

Statistical analysis. Quantitative data are expressed as the means \pm SD of at least 3 replicates. The significance of the differences between the values was assessed using a Student's t-test or analysis of variance (ANOVA) with the Bonferroni multiple comparison test. Values of $\mathrm{P}<0.05$ were considered to indicate statistically significant differences.

\section{Results and Discussion}

Antioxidant and cytotoxic effects of SAMC on JHH7 cells. Both AGEs and their sulfur constituents, such as SAMC and $S$-allyl cysteine (SAC), are recognized as potent antioxidants (21-23). In this study, we first, we examined the antioxidant effects of SAMC on the hepatic cells used in this study. A dose-dependent decrease in cellular ROS levels in the JHH7 cells was observed upon SAMC treatment for $4 \mathrm{~h}$, as detected using CM-H2DCFDA (Fig. 1A and B), while no obvious cytotoxic effect was observed in the JHH7 cells treated with SAMC at concentrations as high as $0.5 \mathrm{mM}$ for $24 \mathrm{~h}$ (Fig. 1C).

Garlic extracts suppressed the AA-induced cellular activation of TG2 in JHH7 cells. We have previously reported that the AA-induced suppression of cell growth accompanies the production of ROS followed by the activation of nuclear TG2 in hepatic cells (17). In this study, we examined the effects of garlic extracts on the activation of TG2 induced by AA (Fig. 2). In accordance with a previous study (17), AA treatment at a concentration of $10 \mu \mathrm{M}$ for $24 \mathrm{~h}$ significantly increased the nuclear activation of TG2 in the JHH7 cells. As the positive control, TG2 activation induced by AA was significantly blocked by the irreversible TG2 inhibitor, ZDON. Notably, co-treatment with AA and either SMAC or AGEs almost completely inhibited the activity of nuclear TG2 to basal levels.

Garlic extracts prevent the AA-induced suppression of the growth of JHH7 cells. Finally, we examined whether the growth-suppressive effects of AA on hepatic cells may be prevented by garlic extracts (Fig. 3). AA treatment for $24 \mathrm{~h}$ 

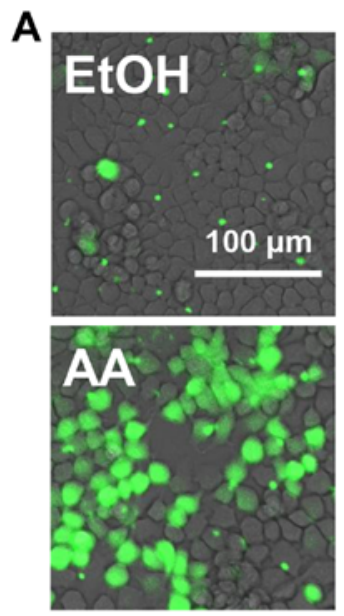

B

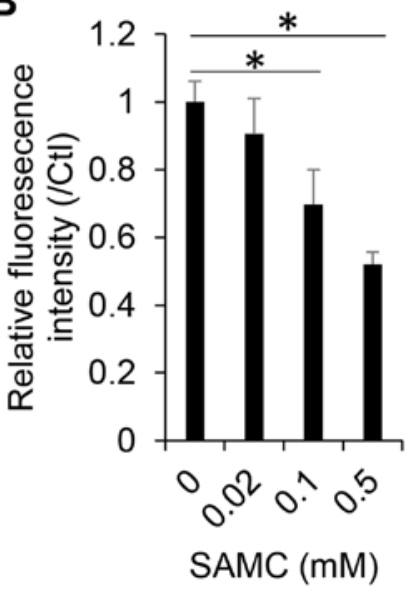

C

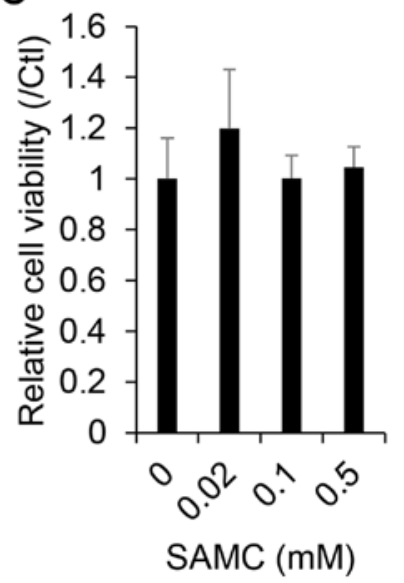

Figure 1. Antioxidant and cytotoxic effects of SAMC on hepatic cells. (A) Representative images of the CM- $\mathrm{H}_{2}$ DCFDA staining of JHH7 cells treated with $\mathrm{EtOH}$ or $10 \mu \mathrm{M} \mathrm{AA}$ for $16 \mathrm{~h}$. (B) A dose-dependent decrease in cellular ROS levels, as measured by CM-H DCFDA staining, following SAMC treatment for $4 \mathrm{~h}$ in JHH7 cells. (C) No cytotoxic effect of SAMC treatment for $24 \mathrm{~h}$ was observed on the JHH7 cells. The data are presented as the means \pm SD; "P $<0.05$, ANOVA with the Bonferroni multiple comparisons test. Ctl, $\mathrm{H}_{2} \mathrm{O}$. SAMC, $S$-allylmercaptocysteine; $\mathrm{CM}-\mathrm{H}_{2} \mathrm{DCFDA}$, chloromethyl derivative of 20,70-dichlorodihydrofluorescein diacetate; AA, arachidonic acid; ROS, reactive oxygen species.
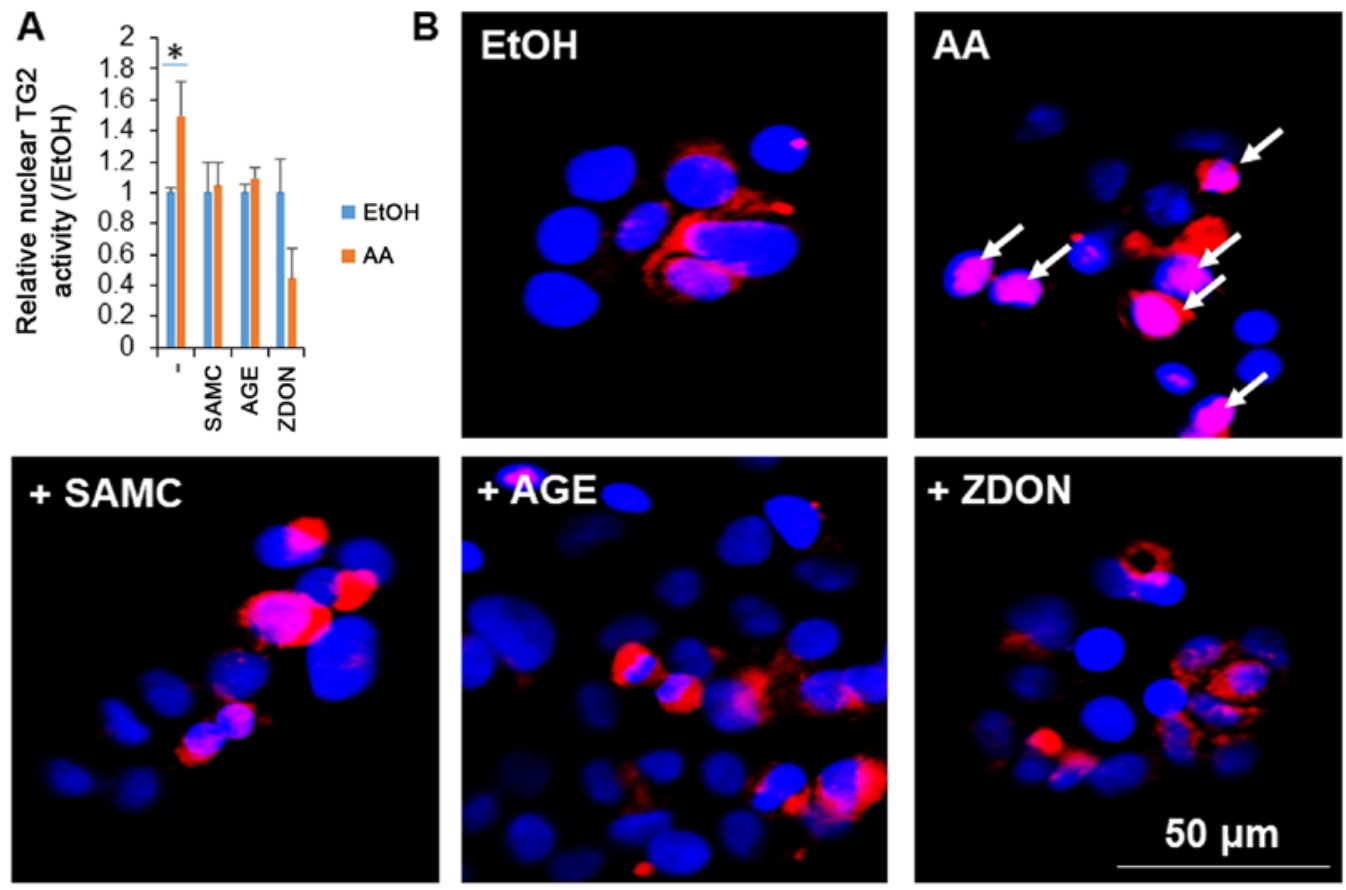

DAPI 5-BAPA

Figure 2. Effect of garlic extracts on AA-induced cellular TG2 activation in hepatic cells. (A) Quantitative data and (B) representative images of the nuclear activity of TG2 in JHH7 cells treated with $20 \mu \mathrm{M}$ AA in the absence or presence of $0.5 \mathrm{mg} / \mathrm{ml}$ AGEs, $0.25 \mathrm{mM}$ SAMC, or $50 \mu \mathrm{M}$ ZDON for $24 \mathrm{~h}$. The cellular activity of TG2 was measured based on the fluorescence intensity resulting from the TRITC-based incorporation of 5-BAPA. White arrows indicated the cells with nuclear activation of TG2. The data are presented as the means \pm SD; "P $<0.05$, Student's t-test. AA, arachidonic acid; TG2, transglutaminase 2; SAMC, $S$-allylmercaptocysteine; AGE, aged garlic extract; ZDON, Z-DON-Val-Pro-Leu-OMe; 5-BAPA, 5-biotinamidopentylamine.

suppressed the viability of the JHH7 cells in a dose-dependent manner. Co-treatment with SMAC, AGEs and ZDON significantly prevented the growth-suppressive effects of AA on the JHH7 cells. Fatty acids are critical constituents of the membrane and serve as energy sources and signal mediators of transduction signals (24). Increasing attention has been paid to the critical roles of unsaturated fatty acids in promoting liver damage and tumorigenesis. SCD1 is a rate-limiting lipid desaturase responsible for generating monounsaturated fatty acids, such as palmitoleic acid and oleic acid. Recently, we reported that the upregulation of SCD1 levels is observed in cancer stem cell (CSC)-like populations compared to non-CSC liver populations within human liver cancer cell lines (25). SCD1-mediated ceramide synthesis has been reported to induce mitochondrial dysfunction, ROS generation and cell apoptosis (26). The protective effects of SCD1 inhibition has 


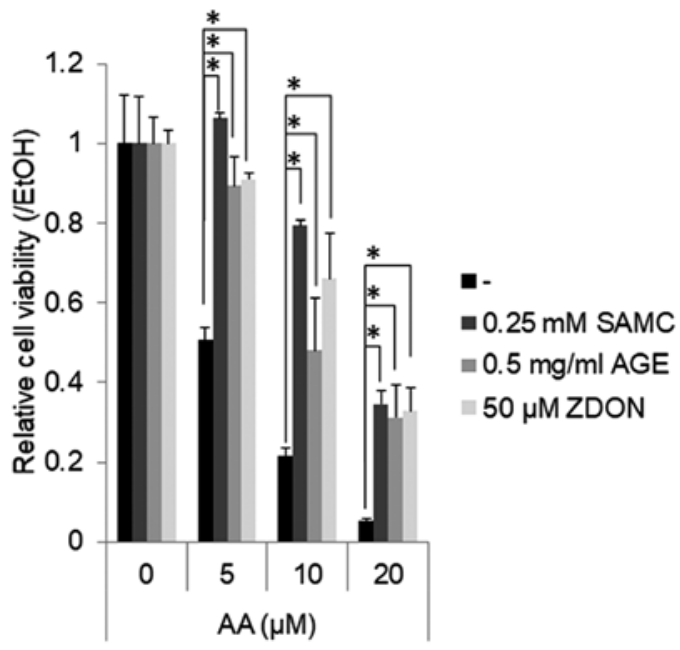

Figure 3. Effects of garlic extracts on AA-induced cell death in hepatic cells. The viability of JHH7 cells treated with increasing concentrations of AA (as indicated) in the absence or presence of $0.25 \mathrm{mM} \mathrm{SAMC}, 0.5 \mathrm{mg} / \mathrm{ml}$ AGEs or $50 \mu \mathrm{M}$ ZDON for $24 \mathrm{~h}$. The data are presented as the means $\pm \mathrm{SD} ;{ }^{*} \mathrm{P}<0.05$, ANOVA with the Bonferroni multiple comparison test. AA, arachidonic acid; SAMC, $S$-allylmercaptocysteine; AGE, aged garlic extract; ZDON, Z-DON-Val-Pro-Leu-OMe.
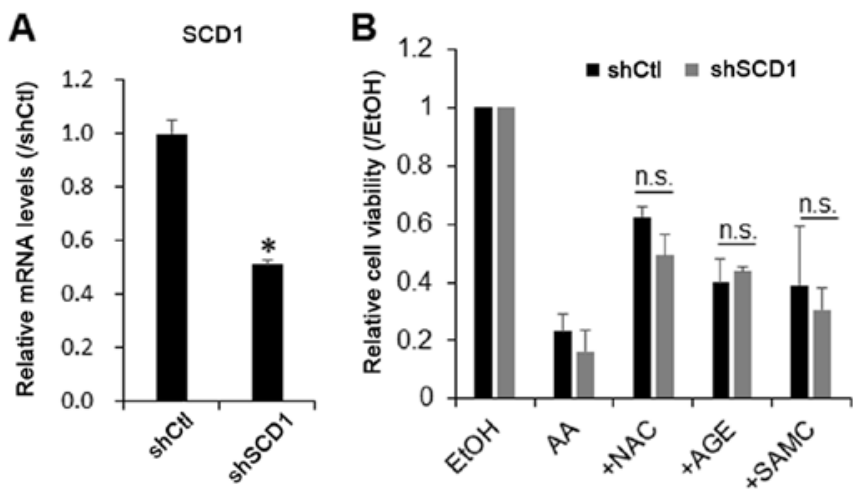

Figure 4. Effects of garlic extracts on the AA-induced death of hepatic cells in which SCD1 was knocked down (A) Gene expression of SCD1 in JHH7 cells transduced with control (shCtl) or SCD1 (shSCD1) shRNA lentiviral particles. (B) The viability of shCtl- and shSCD1-transduced JHH7 cells treated with $20 \mu \mathrm{M}$ AA in the absence or presence of $5 \mathrm{mM}$ NAC, $0.5 \mathrm{mg} / \mathrm{ml} \mathrm{AGEs}$, or $0.25 \mathrm{mM}$ SAMC for $24 \mathrm{~h}$. The data are presented as the means $\pm \mathrm{SD}$; ${ }^{*} \mathrm{P}<0.05$, Student's t-test; n.s., not significant. AA, arachidonic acid; SCD1, stearoyl-CoA desaturase-1; SAMC, $S$-allylmercaptocysteine; AGE, aged garlic extract; NAC, $N$-acetyl-L-cysteine.

been reported to ameliorate ethanol-induced liver injury (27). A SCD1 inhibitor has also been developed to attenuate lipid accumulation and liver injury in a rat model of NASH (28). Therefore, in this study, we examined whether the knockdown of SCD1 prevents the growth-suppressive effect of AA on hepatic cells. For this purpose, the cells were transduced with SCD1 shRNA lentiviral particles, and endogenous SCD1 was stably knocked down by $60 \%$ (Fig. 4A). The knockdown of SCD1 did not significantly affect the growth-suppressive effect of AA or the protective effects of AGEs, SAMC and ZDON against AA on the JHH7 cells (Fig. 4B). These data suggested that AA may directly stimulate cellular ROS production and initiate downstream signaling cascades, including nuclear TG2 activation, leading to the growth suppression of hepatic cells.
Arachidonic acid

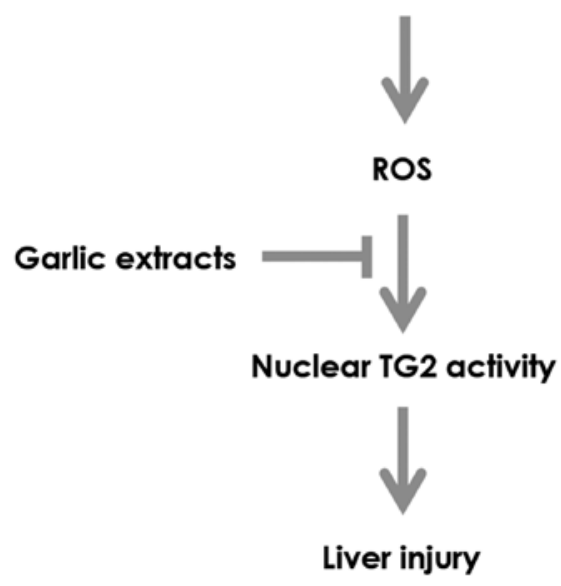

Figure 5. Schematic diagram illustrating the mechanisms through which garlic extracts prevent the AA-induced growth suppression of liver cancer cells by targeting the ROS/TG2-dependent signaling pathway. AA, arachidonic acid; ROS, reactive oxygen species; TG2, transglutaminase 2.

We have previously reported that i) the level of AA is upregulated during liver tumorigenesis (13); ii) the nuclear accumulation of TG2 in hepatic cells results in crosslinking and in the inactivation of the transcription factor Sp1, which leads to the downregulation of Sp1-responsive genes involved in cell survival, and thus resulting in apoptosis (15); and iii) ROS play critical roles in nuclear TG2-dependent AA-induced liver injury (17). In this study, we addressed a potential role of garlic extracts in preventing the growth-suppressive effects of AA on hepatic cells by controlling oxidative stress-mediated cellular TG2 activation (Fig. 5). Opposing roles of TG2 in the onset of liver injury have been reported due to its dual function in the regulation of cell survival and death $(15,29,30)$. Extracellular and cytoplasmic TG2 in the closed form exhibit multiple functions, such as GTPase, cell adhesion and scaffold activities, which are associated with cell growth and may prevent liver injury by favoring tissue stability (31). By contrast, oxidative stress, the $\mathrm{Ca}^{2+}$-dependent protein crosslinking activity of TG2 in the open form and its subcellular location in the nucleus may lead to crosslinking and the inactivation of proliferation-associated transcription factors, such as Sp1, leading to the downregulation of Spl-responsive genes involved in cell survival and resulting in apoptosis (31). This study provides molecular evidence that the mechanism underlying the hepatoprotective effects of garlic extract is associated with the inhibition of the nuclear protein crosslinking activity of TG2. Although the underlying mechanisms are not yet fully understood, it is possible that the antioxidant garlic extracts may suppress the transformation of TG2 from the closed form to the open form, which is essential for the crosslinking activity of TG2 and likely enhances the ability of TG2 to bind importins for nuclear translocation (32).

Panyod et al reported that allicin, a compound in fresh aqueous extracts of garlic, prevented alcohol induced liver injury and inflammation, partly by increasing the hepatic alcohol dehydrogenase activity (10). Colín-González et al (22) and Kodai et al (23) reported that the cytoprotective effects of SAC were associated with the attenuation of oxidative stress. However, this study further provided a mechanistic insight regarding the association between the hepatoprotective effects of garlic extract 
and the inhibition of the TG-related crosslinking of nuclear proteins under oxidative stress conditions. Given the critical roles of unsaturated fatty acids in the maintenance of cancer cell stemness (33) and the loss of cancer immune surveillance (34) in the context of chronic injury, we propose that garlic extracts may serve as a therapeutic option for preventing chronic liver injury and inflammation and the carcinogenesis of fatty livers.

\section{Acknowledgements}

The authors would like to thank Dr T. Oka, Dr K. Tamura and Dr K. Sakata of Wakunaga Pharmaceutical Co., Ltd. for providing AGEs and SAMC.

\section{Funding}

This study was supported by Grants-in-Aid for Young Scientists JP18K15833 (to XYQ) and a Grant-in-Aid for Scientific Research (C) JP18K06976 (to SK) from the Ministry of Education, Culture, Sports, Science and Technology of Japan, the Takeda Science Foundation (to XYQ), and a Research on the Innovative Development and the Practical Application of New Drugs for Hepatitis B Grant JP19fk0310112 from the Japan Agency for Medical Research and Development (to SK).

\section{Availability of data and materials}

All data generated or analyzed during this study are included in this published article or are available from the corresponding author on reasonable request.

\section{Authors' contributions}

XYQ and SK designed the study. XYQ and TS conducted the experiments. XYQ performed the statistical analysis and data interpretation. XYQ, TS and SK wrote the manuscript. All authors have read and approved the final manuscript.

\section{Ethics approval and consent to participate}

Not applicable.

\section{Patient consent for publication}

Not applicable.

\section{Competing interests}

The authors declare that they have no competing interests.

\section{References}

1. Banerjee SK, Mukherjee PK and Maulik SK: Garlic as an antioxidant: The good, the bad and the ugly. Phytotherapy research. PTR 17: 97-106, 2003.

2. Kyo E, Uda N, Kasuga S and Itakura Y: Immunomodulatory effects of aged garlic extract. J Nutr 131 (Suppl 3): 1075S-1079S, 2001.

3. Fratianni F, Riccardi R, Spigno P, Ombra MN, Cozzolino A, Tremonte P, Coppola R and Nazzaro F: Biochemical Characterization and Antimicrobial and Antifungal Activity of Two Endemic Varieties of Garlic (Allium sativum L.) of the Campania Region, Southern Italy. J Med Food 19: 686-691, 2016.
4. Xiao D, Pinto JT, Soh JW, Deguchi A, Gundersen GG, Palazzo AF, Yoon JT, Shirin H and Weinstein IB: Induction of apoptosis by the garlic-derived compound $S$-allylmercaptocysteine (SAMC) is associated with microtubule depolymerization and c-Jun NH(2)-terminal kinase 1 activation. Cancer Res 63: 6825-6837, 2003.

5. Ghyasi R, Mohaddes G and Naderi R: Combination effect of voluntary exercise and garlic (Allium sativum) on oxidative stress, cholesterol level and histopathology of heart tissue in type 1 diabetic rats. J Cardiovasc Thorac Res 11: 61-67, 2019.

6. García-Villalón AL, Amor S, Monge L, Fernández N, Prodanov M, Muñoz M, Inarejos-García AM and Granado M: In vitro studies of an aged black garlic extract enriched in $S$-allylcysteine and polyphenols with cardioprotective effects. J Funct Foods 27: 189-200, 2016.

7. Tsai JC, Chen YA, Wu JT, Cheng KC, Lai PS, Liu KF, Lin YK, Huang YT and Hsieh CW: Extracts from Fermented Black Garlic Exhibit a Hepatoprotective Effect on Acute Hepatic Injury. Molecules 24: pii: E1112, 2019.

8. Wu ZR, Peng-Chen, Yang-Li, Li JY, Xin-Wang, Yong-Wang, Guo DD, Lei-Cui, Guan QG and Li HY: Two cinnamoyloctopamine antioxidants from garlic skin attenuates oxidative stress and liver pathology in rats with non-alcoholic steatohepatitis. Phytomedicine 22: 178-182, 2015.

9. Xiao J, Xing F, Liu Y, Lv Y, Wang X, Ling M-T, Gao H, Ouyang S, Yang M, Zhu J, et al: Garlic-derived compound $S$-allylmercaptocysteine inhibits hepatocarcinogenesis through targeting LRP6/Wnt pathway. Acta Pharm Sin B 8: 575-586, 2018.

10. Panyod S, Wu WK, Ho CT, Lu KH, Liu CT, Chu YL, Lai YS, Chen WC, Lin YE, Lin SH and Sheen LY: Diet Supplementation with Allicin Protects against Alcoholic Fatty Liver Disease in Mice by Improving Anti-inflammation and Antioxidative Functions. J Agric Food Chem 64: 7104-7113, 2016.

11. Starley BQ, Calcagno CJ and Harrison SA: Nonalcoholic fatty liver disease and hepatocellular carcinoma: A weighty connection. Hepatology 51: 1820-1832, 2010.

12. Wong SW, Ting YW and Chan WK: Epidemiology of non-alcoholic fatty liver disease-related hepatocellular carcinoma and its implications. JGH Open 2: 235-241, 2018.

13. Qin XY, Tatsukawa H, Hitomi K, Shirakami Y, Ishibashi N, Shimizu M, Moriwaki H and Kojima S: Metabolome Analyses Uncovered a Novel Inhibitory Effect of Acyclic Retinoid on Aberrant Lipogenesis in a Mouse Diethylnitrosamine-Induced Hepatic Tumorigenesis Model. Cancer Prev Res (Phila) 9: 205-214, 2016

14. Qin XY, Suzuki H, Honda M, Okada H, Kaneko S, Inoue I, Ebisui E, Hashimoto K, Carninci P, Kanki K, et al: Prevention of hepatocellular carcinoma by targeting MYCN-positive liver cancer stem cells with acyclic retinoid. Proc Natl Acad Sci USA 115: 4969-4974, 2018.

15. Tatsukawa H, Fukaya Y, Frampton G, Martinez-Fuentes A, Suzuki K, Kuo TF, Nagatsuma K, Shimokado K, Okuno M, Wu J, et al: Role of transglutaminase 2 in liver injury via cross-linking and silencing of transcription factor Sp1. Gastroenterology 136: 1783-1795.e10, 2009.

16. Shrestha R, Shrestha R, Qin XY, Kuo TF, Oshima Y, Iwatani S, Teraoka R, Fujii K, Hara M, Li M, et al: Fungus-derived hydroxyl radicals kill hepatic cells by enhancing nuclear transglutaminase. Sci Rep 7: 4746, 2017.

17. Qin XY, Lu J, Cai M and Kojima S: Arachidonic acid suppresses hepatic cell growth through ROS-mediated activation of transglutaminase. FEBS Open Bio 8: 1703-1710, 2018.

18. Fujise K, Nagamori S, Hasumura S, Homma S, Sujino H, Matsuura T, Shimizu K, Niiya M, Kameda H, Fujita K, et al: Integration of hepatitis B virus DNA into cells of six established human hepatocellular carcinoma cell lines. Hepatogastroenterology 37: 457-460, 1990.

19. Qin XY, Wei F, Tanokura M, Ishibashi N, Shimizu M, Moriwaki H and Kojima S: The effect of acyclic retinoid on the metabolomic profiles of hepatocytes and hepatocellular carcinoma cells. PLoS One 8: e82860, 2013.

20. Livak KJ and Schmittgen TD: Analysis of relative gene expression data using real-time quantitative PCR and the $2-\Delta \Delta \mathrm{CT}$ method. Methods 25: 402-408, 2001.

21. Rose P, Moore PK and Zhu YZ: Garlic and Gaseous Mediators. Trends Pharmacol Sci 39: 624-634, 2018.

22. Colín-González AL, Santana RA, Silva-Islas CA, Chánez-Cárdenas ME, Santamaria A and Maldonado PD: The antioxidant mechanisms underlying the aged garlic extract- and $S$-allylcysteine-induced protection. Oxid Med Cell Longev 2012: 907162, 2012. 
23. Kodai S, Takemura S, Minamiyama Y, Hai S, Yamamoto S, Kubo S, Yoshida Y, Niki E, Okada S, Hirohashi K, et al: $S$-allyl cysteine prevents $\mathrm{CCl}(4)$-induced acute liver injury in rats. Free Radic Res 41: 489-497, 2007.

24. Eyster KM: The membrane and lipids as integral participants in signal transduction: Lipid signal transduction for the non-lipid biochemist. Adv Physiol Educ 31: 5-16, 2007.

25. Qin XY, Dohmae N and Kojima S: Reply to Yoshida: Liver cancer stem cells: Identification and lipid metabolic reprogramming. Proc Natl Acad Sci USA 115: E6390-E6391, 2018.

26. Chen L, Ren J, Yang L, Li Y, Fu J, Li Y, Tian Y, Qiu F, Liu Z and Qiu Y: Stearoyl-CoA desaturase-1 mediated cell apoptosis in colorectal cancer by promoting ceramide synthesis. Sci Rep 6 : 19665, 2016.

27. Lounis MA, Escoula Q, Veillette C, Bergeron KF, Ntambi JM and Mounier C: SCD1 deficiency protects mice against ethanol-induced liver injury. Biochim Biophys Acta 1861 $1662-1670,2016$

28. Kurikawa N, Takagi T, Wakimoto S, Uto Y, Terashima H, Kono K, Ogata T and Ohsumi J: A novel inhibitor of stearoyl-CoA desaturase-1 attenuates hepatic lipid accumulation, liver injury and inflammation in model of nonalcoholic steatohepatitis. Biol Pharm Bull 36: 259-267, 2013.

29. Nardacci R, Lo Iacono O, Ciccosanti F, Falasca L, Addesso M, Amendola A, Antonucci G, Craxì A, Fimia GM, Iadevaia V, et al: Transglutaminase type II plays a protective role in hepatic injury. Am J Pathol 162: 1293-1303, 2003.
30. Piacentini M, Baiocchini A, Del Nonno F, Melino G, Barlev NA, Rossin F, D'Eletto M and Falasca L: Non-alcoholic fatty liver disease severity is modulated by transglutaminase type 2. Cell Death Dis 9: 257, 2018.

31. Tatsukawa H, Furutani Y, Hitomi $\mathrm{K}$ and Kojima $\mathrm{S}$ : Transglutaminase 2 has opposing roles in the regulation of cellular functions as well as cell growth and death. Cell Death Dis 7: e2244, 2016.

32. Shrestha R, Tatsukawa H, Shrestha R, Ishibashi N, Matsuura T, Kagechika H, Kose S, Hitomi K, Imamoto N and Kojima S: Molecular mechanism by which acyclic retinoid induces nuclear localization of transglutaminase 2 in human hepatocellular carcinoma cells. Cell Death Dis 6: e2002, 2015.

33. Li J, Condello S, Thomes-Pepin J, Ma X, Xia Y, Hurley TD, Matei D and Cheng JX: Lipid Desaturation Is a Metabolic Marker and Therapeutic Target of Ovarian Cancer Stem Cells. Cell Stem Cell 20: 303-314.e5, 2017.

34. Ma C, Kesarwala AH, Eggert T, Medina-Echeverz J, Kleiner DE, Jin P, Stroncek DF, Terabe M, Kapoor V,ElGindi M, et al: NAFLD causes selective CD4(+) T lymphocyte loss and promotes hepatocarcinogenesis. Nature 531: 253-257, 2016.

(i) $\Theta$ This work is licensed under a Creative Commons Attribution-NonCommercial-NoDerivatives 4.0 International (CC BY-NC-ND 4.0) License. 